\title{
Funny current and cardiac rhythm: insights from HCN knockout and transgenic mouse models
}

\section{Annalisa Bucchi, Andrea Barbuti, Dario DiFrancesco and Mirko Baruscotti *}

Department of Biosciences, University of Milano, Milano, Italy

Edited by:

Carol Ann Remme, University of

Amsterdam, Netherlands

\section{Reviewed by:}

Jeanne M. Nerbonne, Washington

University School of Medicine, USA

Dénise Den Haan, Academic Medical

Center Amsterdam, Netherlands

${ }^{*}$ Correspondence:

Mirko Baruscotti, Department of Biosciences, University of Milano, via Celoria 26, 20133 Milano, Italy. e-mail:mirko.baruscotti@unimi.it
In the adult animal the sinoatrial node (SAN) rhythmically generates a depolarizing wave that propagates to the rest of the heart. However, the SAN is more than a simple clock; it is a clock that adjusts its pace according to the metabolic requirements of the organism. The Hyperpolarization-activated Cyclic Nucleotide-gated channels (HCN1-4) are the structural component of the funny $\left(I_{f}\right)$ channels; in the SAN the $I_{f}$ current is the main driving electrical force of the diastolic depolarization and the HCN4 is the most abundant isoform. The generation of $\mathrm{HCN} \mathrm{KO}$ and transgenic mouse models has advanced the understanding of the role of these channels in cardiac excitability. The HCN4 KO models that were first developed allowed either global or cardiac-specific constitutive ablation of HCN4 channels, and resulted in embryonic lethality. A further progress was made with the development of three separate inducible HCN4 KO models; in one model KO was induced globally in the entire organism, in a second, ablation occurred only in HCN4-expressing cells, and finally in a third model KO was confined to cardiac cells. Unexpectedly, the three models yielded different results; similarities and differences among these models will be presented and discussed. The functional effects of HCN2 and HCN3 knockout models and transgenic $\mathrm{HCN} 4$ mouse models will also be discussed. In conclusion, $\mathrm{HCN} \mathrm{KO/transgenic} \mathrm{models}$ have allowed to evaluate the functional role of the $I_{f}$ currents in intact animals as well as in single SAN cells isolated from the same animals. This opportunity is therefore unique since it allows (1) to verify the contribution of specific $\mathrm{HCN}$ isoforms to cardiac activity in intact animals, and (2) to compare these results to those obtained in single cell experiments. These combined studies were not possible prior to the development of $\mathrm{KO}$ models. Finally, these models represent critical tools to improve our understanding of the molecular basis of some inheritable arrhythmic human pathologies.

Keywords: HCN KO mouse models, cardiac pacemaking, sinoatrial node

\section{INTRODUCTION}

In mammals, cardiac pacemaking originates from cells in the sinoatrial node (SAN) constitutively able to generate rhythmic action potentials (APs) due to the presence of a spontaneous diastolic depolarization (Boyett et al., 2000; Mangoni and Nargeot, 2008). SAN physiologists have long studied the molecular mechanisms responsible for the diastolic/pacemaker depolarization since it is this phase that temporally separates and electrically triggers consecutive APs (DiFrancesco et al., 1986; Biel et al., 2009; Baruscotti et al., 2010a). Several ionic currents and mechanisms that contribute to SAN cell's activity are shared with other types of cardiomyocytes; however, the functional expression of the "funny" $\left(I_{\mathrm{f}}\right)$ current in the adult is mostly restricted to the SAN and the conduction system (Baruscotti et al., 2010a).

Its tissue-specific expression, together with the evidence that $I_{\mathrm{f}}$ is an inward depolarizing current activated within the diastolic depolarization range of potentials $(-40 /-60 \mathrm{mV})$ and modulated by the second messenger cAMP, clearly indicate that this current provides a substantial contribution to cardiac pacemaking (Baruscotti et al., 2005; Verkerk et al., 2007a). Since its discovery and until a decade ago, the vast majority of studies on the $I_{\mathrm{f}}$ current were carried out in single SAN cells isolated from lower mammals, typically rabbit; recent evidence in humans has confirmed previous conclusions on $I_{\mathrm{f}}$ properties and function. More specifically: (1) the presence of $I_{\mathrm{f}}$ and HCN1 and HCN4 isoforms has been verified also in human SAN cells (Verkerk et al., 2007a,b; Chandler et al., 2009); (2) genetically determined alterations of the $I_{\mathrm{f}}$ channel have been associated with mild or severe forms of arrhythmias in humans (Baruscotti et al., 2010b); (3) an $I_{\mathrm{f}}$ specific blocker, ivabradine, acts as pure heart rate slowing drug and is currently used in the therapy of chronic stable angina and heart failure (DiFrancesco and Camm, 2004).

The molecular determinants of the funny current belong to the family of Hyperpolarization-activated Cyclic Nucleotide-gated ( $\mathrm{HCN})$ channels which comprises four isoforms (HCN1-4; Barbuti et al., 2007; Biel et al., 2009). The subunits can assemble as homotetramers and/or heterotetramers to form functional channels. The structural arrangement of each single subunit comprises six membrane-spanning domains (S1-S6), which include a putative voltage sensor $(\mathrm{S} 4)$ and a pore $(\mathrm{P})$ region between the $\mathrm{S} 5$ and S6 segments, and a cyclic-nucleotide-binding domain (CNBD) in the $\mathrm{C}$-terminus. 
Analysis of HCN distribution in the adult heart indicates that the HCN4 isoform is the major component of pacemaker channels in the SAN of all the species analyzed (mouse, rat, rabbit, dog, human). Species-dependent expression of HCN1 and HCN2 has also been reported in the SAN, but always at much lower levels than HCN4; the HCN3 is absent from the SAN; (Ishii et al., 1999; Shi et al., 1999; Moosmang et al., 2001; Marionneau et al., 2005; Tellez et al., 2006; Liu et al., 2007; Thollon et al., 2007; Stillitano et al., 2008; Brioschi et al., 2009; Chandler et al., 2009; Fenske et al., 2011; Herrmann et al., 2011b). A clear understanding of the presence of different $\mathrm{HCN}$ isoforms in working myocytes is complicated because of interspecies variability and of contrasting results between transcriptional and protein data. Despite this, it is reasonable to say that $\mathrm{HCN} 2$ is the predominant isoform both in atria and ventricles even though at a lower level of expression compared to the HCN4 level in SAN and the conduction system. HCN4, HCN3, and HCN1 proteins are only occasionally reported (Shi et al., 1999; Han et al., 2002; Dobrzynski et al., 2003; Marionneau et al., 2005; Zicha et al., 2005; Yamamoto et al., 2006; Liu et al., 2007; Stillitano et al., 2008; Chandler et al., 2009; Fenske et al., 2011; Herrmann et al., 2011b). Taken together, the observations outlined above and a whole set of experimental findings and numerical reconstruction data (Baruscotti et al., 2005; DiFrancesco, 2010) indicate clearly the involvement of the $I_{\mathrm{f}}$ current in cardiac pacemaking. What is the degree of $I_{\mathrm{f}}$ involvement in the complex set of mechanisms that underlie the whole of the cellcycling processes active in pacemaker cells is however still a very much debated issue (Lakatta and DiFrancesco, 2009; DiFrancesco and Noble, 2012a,b). To determine this, it is also important to consider that despite the copious amount of studies carried out at single cell, any conclusion deriving from this work cannot automatically be held valid for the function of the SAN as a whole, in the absence of experimental confirmation. The availability of the knockout technology has finally allowed to explore the role of the $I_{\mathrm{f}}$ current within its complex setting of interactions in the living animal and the pathological states associated with its removal.

\section{HCN4 KO AND TRANSGENIC MOUSE MODELS AND EMBRYOLOGICAL DEVELOPMENT}

$\mathrm{HCN} \mathrm{KO}$ and transgenic mice have allowed to gain insight on the role of HCN subunits during embryonic development (Table 1). Constitutive deletion of the HCN4 gene, either globally or specifically in the myocardium, causes a premature death of homozygous embryos between ED9.5 and ED11.5 (Stieber et al., 2003). Analysis of isolated ED9.5 hearts revealed that HCN4 deletion results in a significant bradycardia (36.7\% reduction of heart rate when compared to wild type animals). The HCN4 knockout resulted in a $75-90 \%$ decrease of the $I_{\mathrm{f}}$ current, with the residual current being possibly also carried by HCN1 and HCN2 according to the authors (Stieber et al., 2003). These data confirm that the $\mathrm{HCN} 4$ isoform is the major component of the f-channel also in the developing SAN. Importantly, studies with specific deletion of $\mathrm{HCN} 1$ and HCN2 indirectly confirmed the role of HCN4 since in these HCN1 (Nolan et al., 2003) and HCN2 (Ludwig et al., 2003) knockout animals there was no evidence of cardiac alterations in developing embryos. The fundamental role of HCN4 during cardiac development is supported also by molecular data on the distribution of HCN4 mRNA in the embryonic heart. In the mouse, the Hcn4 gene is indeed already expressed in the cardiac mesoderm at ED7.5; with the progression of development this expression remains confined to the sinus venosus/SAN and to the conduction system (Garcia-Frigola et al., 2003; Christoffels et al., 2010; Vicente-Steijn et al., 2011).

Recently, a similar pattern of HCN4 expression has been found in the chick embryo (Vicente-Steijn et al., 2011). This early expression of HCN4 is in agreement with previous evidence that in the chick embryonic heart, pacemaker activity initiates from the sinus venosus (the prospective SAN) before the first contraction takes place (DeHaan, 1965; Van Mierop, 1967). In mice, the first cardiac contraction is visible around embryonic day 8.5 (ED8.5) at the tubular heart stage, and at this stage most cardiomyocytes display rhythmic contractions and express the $I_{\mathrm{f}}$ current (Yasui et al., 2001). After this period, the proportion of cardiac embryonic cells maintaining a spontaneous activity decreases by about $60-70 \%$, a decrease that is accompanied by a significant reduction $(\sim 80 \%)$ of the current (Yasui et al., 2001).

Maintenance of a regular, if slower, rate until ED11.5 following deletion of HCN4 suggests that other mechanisms contribute to cardiac pacemaking in these early stages. Why HCN4 is then robustly expressed so early in the developing heart? A possible answer comes from the analysis of another transgenic HCN model. Recently Harzheim et al. (2008) have developed a mouse carrying a single amino acid substitution (R669Q) within the CNBD of HCN4 which makes the subunit completely insensitive to cAMP stimulation. Surprisingly, $\mathrm{HCN} 4^{\mathrm{R} 669 \mathrm{Q} / \mathrm{R} 669 \mathrm{Q}}$ homozygous mice die at ED111-ED12 and before that time point they show a reduced heart rate similar to that of both global and cardiac-specific constitutive HCN4 KO mice. When HCN4 protein expression and $I_{\mathrm{f}}$ current were analyzed in $\mathrm{HCN} 4^{\mathrm{R} 669 \mathrm{Q} / \mathrm{R} 669 \mathrm{Q}}$ mice, they did not show any down-regulation and the only difference was the expected lack of sensitivity to cAMP with a consequent activation at more negative potentials. These data indicate that, although HCN4 channels contribute to pacemaking as soon as the tubular heart starts to contract, their contribution becomes more important after ED9.5 when the SAN starts to develop from mesenchymal precursors (Wiese et al., 2009). At ED12.5, when the SAN is formed, $\mathrm{HCN} 4^{\mathrm{R} 669 \mathrm{Q} / \mathrm{R} 669 \mathrm{Q}}$ channels failure to respond to adrenergic stimulation becomes incompatible with life as previously indicated (Portbury et al., 2003; Chandra et al., 2006). Other evidence confirming the importance of HCN4 channels during embryonic development derives from another $\mathrm{KO}$ mouse with a constitutive deletion of Shox2, a transcription factor participating in the specific development of the SAN (Christoffels et al., 2010). The removal of shox2 does not cause any functional alterations in the heart up to ED10.5 when a severe bradycardia (50\% compared to wild type animals) and a decrease of HCN4 expression become evident. Shox2-deleted mice die between ED11.5 and ED12.5 (Espinoza-Lewis et al., 2009) as observed with HCN4 KO mice.

\section{ROLE OF HCN4 CHANNELS IN ADULT MICE}

Previous studies using constitutive global or cardiac-specific deletion of HCN4 isoforms (Stieber et al., 2003) have revealed that the presence of HCN4 is required for the correct functional development of the embryonic heart; nonetheless the prenatal lethality 
Table 1 | Phenotypic manifestations of $\mathrm{HCN} \mathrm{KO/transgenic} \mathrm{mouse} \mathrm{models.}$

\begin{tabular}{|c|c|c|c|c|}
\hline Models & In vivo effects in embryos & Isolated heart & Isolated cardiomyocytes & Reference \\
\hline Constitutive global HCN4 KO & Embryonic lethality (ED 9.5-11.5) & & & Stieber et al. (2003) \\
\hline $\mathrm{HCN} 4 \mathrm{KO}$ & Embryonic lethality (ED 9.5-11.5) & $\begin{array}{l}\downarrow \mathrm{HR}(-36.7 \%) \\
\text { No response to cAMP }\end{array}$ & $\begin{array}{l}I_{\mathrm{f}}: \downarrow(-75 /-90 \%) \\
\text { No response to cAMP } \\
\text { APs: absence of mature } \\
\text { Pacemaker-like APs } \\
\text { No response to cAMP }\end{array}$ & Stieber et al. (2003) \\
\hline \multirow[t]{2}{*}{$\begin{array}{l}\text { Constitutive global } \\
\text { HCN4 }\end{array}$} & Embryonic lethality (ED 11-12) & $\begin{array}{l}\downarrow \mathrm{HR}(-40 /-60 \%) \\
\text { No response to Iso }\end{array}$ & $\begin{array}{l}\text { If: slower activation and } \\
\text { shift of the AC }(-13 \mathrm{mV}) \\
\text { No response to cAMP } \\
\text { APs: } \downarrow \text { rate }(-36 /-56 \%)\end{array}$ & Harzheim et al. (2008) \\
\hline & In vivo effects in adult & Isolated SAN cells & & \\
\hline Inducible global HCN4 KO & $\begin{array}{l}\text { Sinus arrhythmias(pauses) } \\
\text { Normal response to Iso }\end{array}$ & $\begin{aligned} & I_{\mathrm{f}}:(-75 \%) \\
& \text { Faster activation; } r \\
& \text { Normal response } \\
& \text { APs: no spontaneous a } \\
& \text { when present, spo }\end{aligned}$ & $\begin{array}{l}\text { shift of the AC } \\
\text { so } \\
\text { vity in } 90 \% \text { of the cells; } \\
\text { aneous rate is normal }\end{array}$ & Herrmann et al. (2007) \\
\hline cells HCN4 KO (KiT-HCN4 KO) & $\begin{array}{l}\text { Arrhythmia (sinus pauses) } \\
\text { Normal response to Iso } \\
\uparrow \text { Response to Carb }\end{array}$ & $\begin{array}{r}I_{\mathrm{f}}: \downarrow(-80 \%) \\
\text { Faster activation, } r \\
\text { APs: no spontaneous a } \\
\text { when present, spo }\end{array}$ & $\begin{array}{l}\text { shift of the } A C \\
\text { vity in } 45 \% \text { of the cells; } \\
\text { aneous rate is normal }\end{array}$ & Hoesl et al. (2008) \\
\hline \multirow[t]{2}{*}{ HCN4 KO (Ci-HCN4 KO) } & $\downarrow$ Basal HR (-50\%) & $\begin{aligned} I_{\mathrm{f}}: & \downarrow(-70 \%) \\
& \text { No changes in kine }\end{aligned}$ & $S$, no shift of the $A C$ & Baruscotti et al. (2011) \\
\hline & $\begin{array}{l}\text { PQ prolongation } \\
\downarrow \text { Maximal response to Iso } \\
\text { AV block and death }\end{array}$ & $\begin{aligned} \text { Normal response } & \\
\text { APs: } & \downarrow \text { Rate }(-61 \%) \\
& \downarrow \text { Maximal respon }\end{aligned}$ & $\begin{array}{l}\text { so } \\
\text { to Iso }\end{array}$ & \\
\hline \multirow[t]{2}{*}{ HCN4-573X KI } & $\downarrow$ Basal HR (-20\%) & $\begin{array}{l}I_{\mathrm{f}}: \text { no reduction } \\
\text { Slower activation; } \\
\text { No response to Is }\end{array}$ & $\mathrm{ft}$ of the $\mathrm{AC}(-20 \mathrm{mV})$ & Alig et al. (2009) \\
\hline & $\downarrow$ Exercise-induced HR & 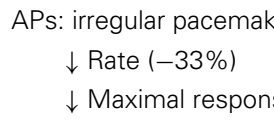 & $\begin{array}{l}\text { activity in } 88 \% \text { of the cells } \\
\text { to Iso }\end{array}$ & \\
\hline Constitutive global HCN2 KO & $\begin{array}{l}\text { Absence epilepsy and sinus } \\
\text { dysrhythmia }\end{array}$ & $\begin{aligned} I_{\mathrm{f}}: \downarrow & (-30 \%) \\
& \text { Slower activation; } \\
& \text { Normal response }\end{aligned}$ & $\begin{array}{l}\text { shift of the AC } \\
\text { AMP }\end{array}$ & Ludwig et al. (2003) \\
\hline $\begin{array}{l}\text { Constitutive cardiac-specific } \\
\text { HCN2 KO }\end{array}$ & Sinus dysrhythmia & & & Ludwig et al. (2003) \\
\hline Constitutive global HCN3 KO & $\begin{array}{l}\text { Regular sinus rhythm } \\
\uparrow \text { T-wave amplitude }(+63.5 \%) \text { and } \\
\text { duration }(+15 \%) \text { at low heart rates } \\
\uparrow \text { QT interval }(+12 \%)\end{array}$ & $\begin{array}{l}\text { Isolated epicardial ce } \\
I_{f}: \downarrow(-30 \%) \\
\text { APs: shortening of the }\end{array}$ & duration & Fenske et al. (2011) \\
\hline
\end{tabular}

associated with this model has prevented further investigation of the role of the $I_{\mathrm{f}}$ current in adult cardiac pacemaking. This aspect was therefore addressed by means of temporally controlled induction of gene knockout methodology.

\section{INDUCIBLE KO MODELS}

The first inducible HCN4 KO model was developed in 2007 by Herrmann et al. (2007) who engineered a transgenic mouse line by inserting LoxP sites in the regions flanking the exon 4 of the Hcn 4 gene (encoding the pore and the S6 transmembrane domain). This line was then crossed with the CAGGCre-ERTM mouse line (Hayashi and McMahon, 2002) to ensure the ubiquitous expression of a tamoxifen-inducible Cre construct and thus a generalized removal of the HCN4 isoforms from the entire organism. The following year the same group (Hoesl et al., 2008) produced a new transgenic mouse line with an inducible Cre inserted inframe into the Hcn4 start codon; thus allowing the knockout event to occur only in HCN4-expressing cells. The effective deletion of HCN4 channels was confirmed in both models by PCR, western blot, and immunoistochemical detection experiments, and by patch-clamp studies in single SAN cells isolated from $\mathrm{KO}$ mice; the latter showed that the $I_{\mathrm{f}}$ current decreased of about $75-80 \%$. Despite this large current reduction, ECG recordings in freely moving HCN4 KO mice did not reveal major alterations of the cardiac 
electrical activity. The only evidence of an arrhythmic behavior was the presence of sinus pauses ( $8-16$ pauses/min with an average duration of $321 \mathrm{~ms}$ ) between periods of normal activity characterized by mean basal rates which did not differ from that of control mice. Interestingly, the number of pauses was inversely related to the heart rate, and the highest number of pauses (up to $8.1 / \mathrm{min}$ ) occurred at heart rates of about 300-450 bpm; the presence of sinus pauses was also confirmed in ECG recordings of isolated hearts (Herrmann et al., 2007). Studies of spontaneous activity of isolated single SAN cells did not produce similar results since the authors report that a large fraction (45-90\%) of the cells lack the ability to fire spontaneously (Herrmann et al., 2007; Hoesl et al., 2008) and in those cells in which repetitive APs were present, their features did not differ from those observed in SAN cells from wild type animals. This remarkable difference between the appearance of sinus pauses in the intact animal/isolated heart and the lack of normal spontaneous activity as observed in single cells remains an issue for which a convincing explanation is still lacking.

The $I_{\mathrm{f}}$ current has previously been shown to be an important target of autonomic modulators and single cells studies have shown that the $\beta$-adrenergic/muscarinic modulation of single cell firing rate reflects the increased/reduced $I_{\mathrm{f}}$ current flowing during diastole (Bucchi et al., 2007; Mangoni and Nargeot, 2008). For this reason these mouse models were also employed to verify whether autonomic modulation of heart rate could be altered in the absence of HCN4 channels. Maximal sympathetic activation due to isoproterenol administration $(0.5 \mathrm{mg} / \mathrm{kg}$ i.p. $)$ or physical exercise (treadmill) in freely moving HCN4 knockout mice elicited a rate response that was not different from that of control mice $(\sim 700 \mathrm{bpm})$, but upon return to basal rate the number of pauses observed in $\mathrm{KO}$ mice was increased up to fourfold (Herrmann et al., 2007). Perhaps a more interesting finding came from muscarinic stimulation since the heart rate reduction observed in $\mathrm{HCN} 4 \mathrm{KO}$ mice was significantly larger than that elicited in control mice, thus suggesting that the depolarizing contribution of $\mathrm{HCN} 4$ channels may be required to partially counteract the bradycardic effect due to strong activation of the parasympathetic arm of the sympathovagal balance (Herrmann et al., 2007; Hoesl et al., 2008).

Taken together, the results obtained with these inducible models suggest that ablation of HCN4 in the adult animal has limited effects on cardiac pacemaker generation and modulation. These results appear therefore to challenge the previously accepted idea that considered the $I_{\mathrm{f}}$ current/HCN4 channels a major determinant of SAN pacemaking.

However, a pitfall of the previous inducible models was the lack of cardiac-specificity. Indeed, both the generalized removal of the HCN4 isoform in the entire organism (Herrmann et al., 2007) and the selective ablation only in HCN4-expressing cells (Hoesl et al., 2008) imply that HCN4 knockout occurs not only in the heart, but also in brain areas expressing the HCN4 channels. It is therefore likely that neuronal- and cardiac-induced effects of the KO process overlap thus confounding the interpretation of data. In order to allow for a cardiac-specific HCN4 removal, our group developed a mouse knockout model by crossing a novel floxed HCN4 mouse line (Baruscotti et al., 2011) with a Cre mouse carrying the Crerecombinase under the control of the cardiac-specific $\alpha$-myosin heavy chain $(\alpha \mathrm{MHC})$ promoter (Sohal et al., 2001). This knockout protocol ensures an inducible and cardiac-restricted ablation of the HCN4 isoforms. In this model the loxP sites were inserted in the region flanking the exon 2 which encodes for the region comprising most of the S1 up to the entire S4 transmembrane segments. The recombination process led to a frame-shift generating an early stop codon but it is not known whether the putative truncated protein is made or not (Figure 1A). The knockout process was induced by i.p. injection of tamoxifen for five consecutive

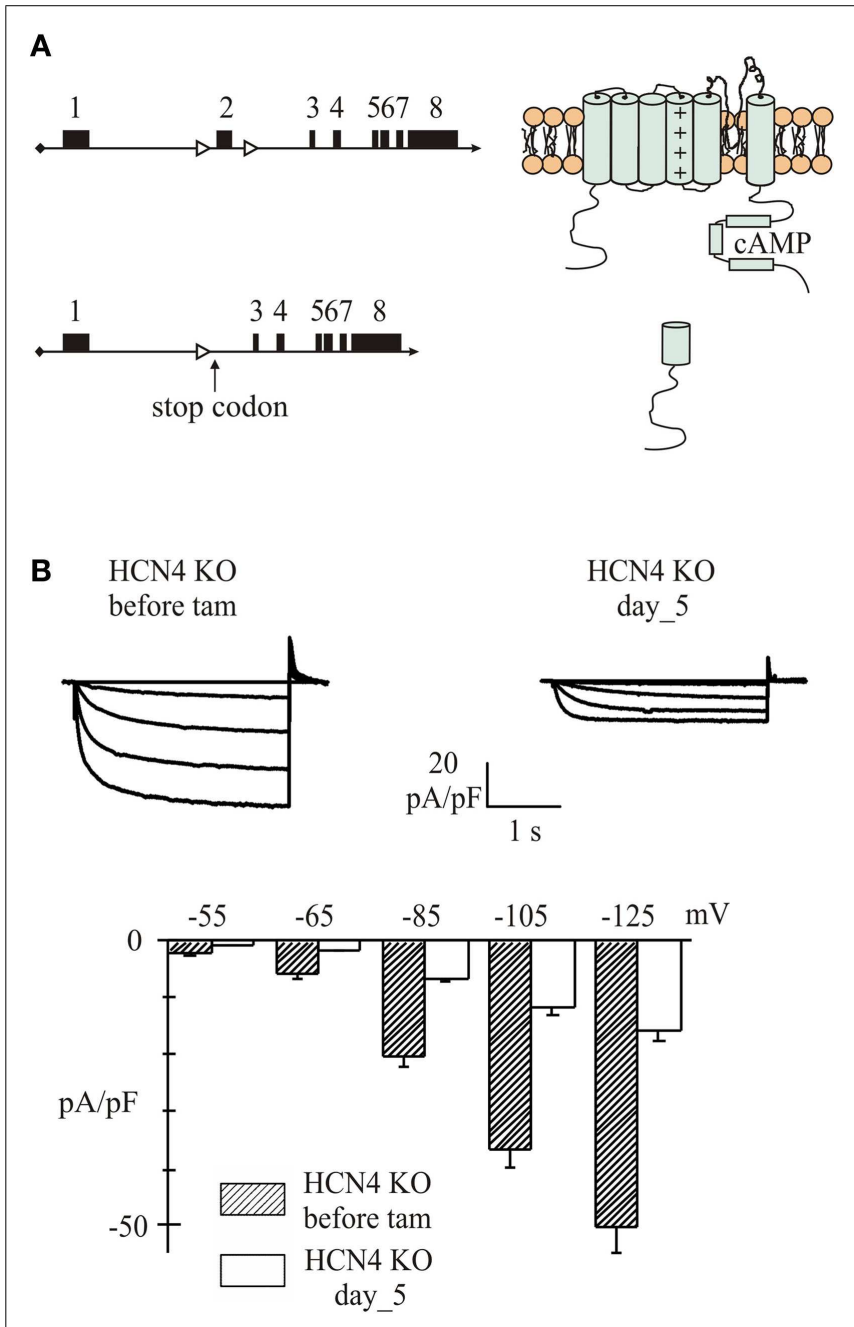

FIGURE 1 | (A) Top, left: structure of the floxed HCN4 gene carrying the loxP sites (triangles) in the introns flanking exon 2 of the inducible cardiac-specific HCN4 KO mouse model. Top, right: structure of the wild type HCN4 protein isoform. Bottom, left: HCN4 gene structure after the Cre-induced recombination; the gene is now lacking exon 2. Bottom, right: Removal of exon 2 eliminates the first four transemembrane segments and generates a frame-shift leading to an early stop-codon 3 residues downstream to the recombination site. The hypothetical resulting protein should therefore be formed by the $\mathrm{N}$-terminus and by a small portion of the S1 segment. No data on the presence/absence of both transcript and protein are available (B) Bottom: Mean $I_{f}$ current densities measured during hyperpolarization steps at the indicated potentials (holding potential $-35 \mathrm{mV}$ ) from SAN cells isolated from cardiac-specific HCN4 KO mice before (dashed bars) and 5 days after (empty bars) KO induction (tamoxifen treatment). Top: Representative $I_{\mathrm{f}}$ traces recorded at the same potentials. 
days. This model yielded completely different results than previous non-cardiac-specific models.

The KO induction in freely moving mice resulted in the development of a progressive slowing of the heart rate, without the appearance of anomalous sinus pauses. Five days after the initiation of the tamoxifen treatment, the average heart rate observed by telemetric ECG recordings was reduced by about $50 \%$ relative to control (Figure 2). In this model, therefore, removal of $\mathrm{HCN} 4$ channels was clearly associated with the appearance of severe bradycardia. The effective ablation of $\mathrm{HCN} 4$ proteins was confirmed by immunolabeling of SAN tissue and single cells and by western blot experiments; patch-clamp recordings quantified the $\mathrm{KO}$ effect in a $70 \%$ reduction of the $I_{\mathrm{f}}$ current (Figure 1B). The cellular origin of the bradycardia was then further investigated

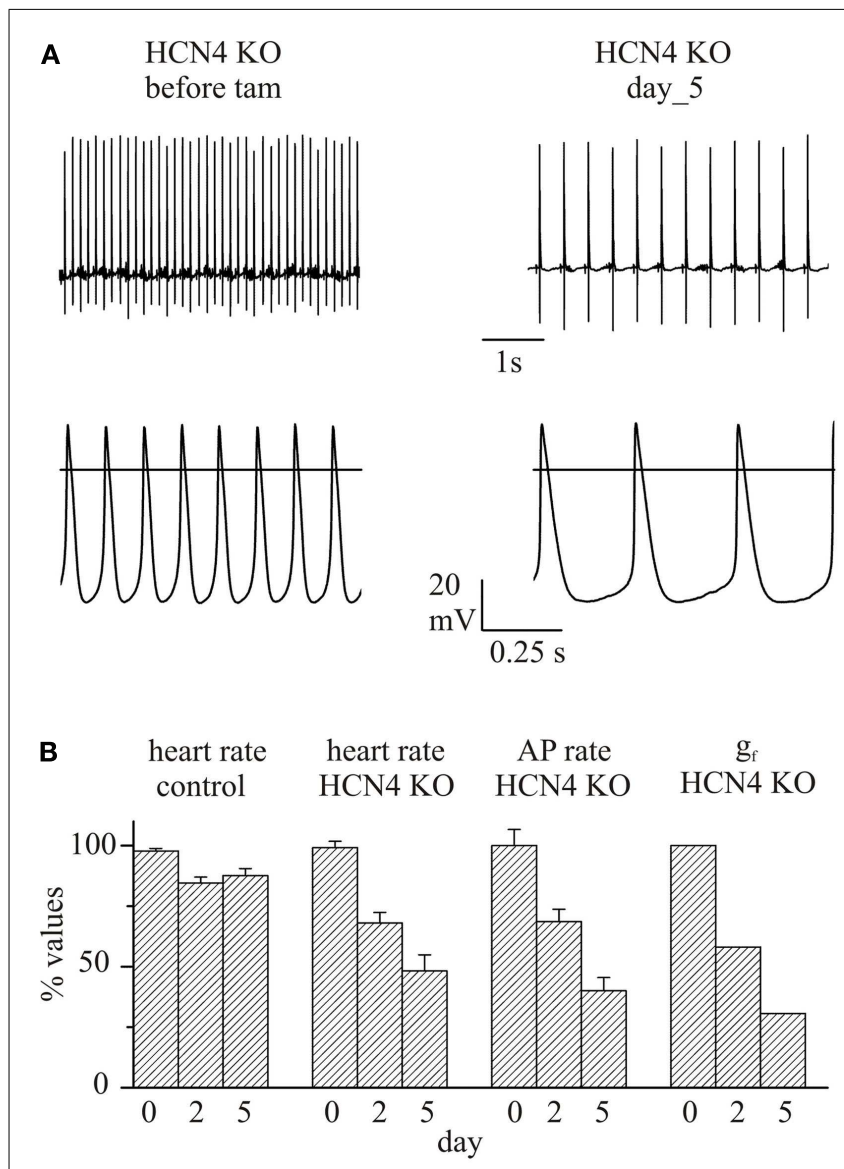

FIGURE 2 | (A) Top: Representative telemetric ECG traces recorded from freely moving mice before (left) and after (right) cardiac-specific HCN4 ablation (five tamoxifen injections). Bottom: Sample action potentials recorded from SAN cells isolated before (left) and after (right) the knockout. (B) Bar-graph showing normalized telemetric heart rates of control (left) and $\mathrm{KO}$ (middle left) mice recorded before (day 0 ) and during the Tam-procedure (day 2 and day 5). The normalized spontaneous activity (middle right) and the $I_{\mathrm{f}}$ current conductance (right) of SAN cells isolated from $\mathrm{KO}$ mice in the same days. Clearly the induction of the knockout decreases the heart rates of freely moving animals, the spontaneous activity of isolated SAN cells, and the $I_{f}$ current conductance (gf) in a similar manner. Only a minor heart rate reduction was observed in control animals undergoing the same treatment. by comparing the spontaneous activity of single SAN cells isolated from control and $\mathrm{KO}$ animals. $\mathrm{KO}$ induction reduced but did not abolish the spontaneous firing of SAN cells (by about 61\% at day 5 ) and the time-course of this effect nicely overlapped the bradycardic onset in intact animals (Figure 2B). Clearly, the similar time courses of heart rate bradycardia and slowing of spontaneous firing of single cells, proceeding in parallel with the reduction of the $I_{\mathrm{f}}$ current, indicate a strict correlation between $I_{\mathrm{f}}$ current and rate.

This knockout model also allowed the evaluation of the relevance of the $I_{\mathrm{f}}$ current to the modulation of the cardiac rate induced by $\beta$-adrenergic activation. Isoproterenol stimulation (Iso, $0.1 \mathrm{mg} / \mathrm{kg}$, i.p.) increased rate in both control and $\mathrm{KO}$ mice but maximal rate values were significantly different ( 705 vs. $485 \mathrm{bpm}$, respectively). In agreement with the results in intact animals, the average maximal rate of spontaneously beating single cells perfused with Iso $(1 \mu \mathrm{M})$ was significantly higher in control cells (489 bpm) than in KO SAN cells $(280 \mathrm{bpm})$. Despite these differences in maximal rates, the Iso-induced accelerations were similar in telemetric recordings from control and KO animals (193 vs. $185 \mathrm{bpm}$, respectively) and in single control and HCN4 KO SAN cells ( $120 \mathrm{vs.} 143 \mathrm{bpm}$, respectively). The evidence that knockout of HCN4 channels reduces both basal rate and maximal $\beta$-adrenergic response in intact animals and in single cells provides a direct demonstration that the $I_{\mathrm{f}}$ current plays a prominent role in basal rhythm generation and modulation.

Bradycardia and chronotropic incompetence were not the only effects observed in the cardiac-specific HCN4 knockout model. HCN4 knockout also leads to a prolongation of the PQ interval (from $32.7 \mathrm{~ms}$ before induction to $45.6 \mathrm{~ms}$ after full tamoxifen treatment) and AV block, eventually leading to heart arrest and death of the animal. During AV block, sinus rhythm was always present albeit with a reduced rate. The unexpected observation that HCN4 KO impairs more dramatically the AVN than the SAN function (i.e., the AVN is more sensitive than the SAN to f-channel removal) remains a significant and intriguing result that awaits further confirmation and interpretation.

\section{COMPARISON AMONG ADULT INDUCIBLE HCN4 KNOCKOUT MODELS}

Ideally all adult HCN4 KO models investigated should have yielded similar or at least coherent results, which however were not observed. Herrmann and Hoesl's models (Herrmann et al., 2007; Hoesl et al., 2008) led to the conclusion that the $I_{\mathrm{f}}$ current does not substantially contribute to basal heart rate or rate acceleration induced by sympathetic stimulation. On the contrary, our cardiac-specific model revealed strong effects since a $50 \%$ reduction in rate was observed in $\mathrm{KO}$ mice, all mice died due to complete $\mathrm{AV}$ block, and chronotropic response to maximal $\beta$ stimulation was about $30 \%$ smaller than in control mice. We do not have a simple explanation for the observation that complete and HCN4expressing restricted knockout do not lead to the deep bradycardia observed with cardiac-specific knockout. However, in addition to the intrinsic difference in the models, two additional aspects should be considered. A first difference between our KO mice and Herrmann and Hoesl's (Herrmann et al., 2007; Hoesl et al., 2008) is that while in Herrmann and Hoesl's models the knockout procedure ablates exon 4, and does not produce a frame-shift of the remaining sequence, our model ablates exon 2 and generates a 
stop codon three residues downstream the site of recombination (Baruscotti et al., 2011). Whether this difference may or may not produce any different results is not clear, since apparently both procedures generate non-functional channels. The second aspect relates to the genetic background of the mice. Although all the discussed mouse models have the same C57BL6 genetic background, this does not necessarily mean that they are genetically similar since recent evidence indicates the existence of multiple C57BL6 sub-strains (Kiselycznyk and Holmes, 2011), and significant phenotypic differences among sub-strains have been reported (Blum et al., 1982; Bryant et al., 2008; Matsuo et al., 2010). We therefore cannot fully rule out that some functional differences among $\mathrm{HCN} 4 \mathrm{KO}$ and transgenic models may arise from the combination of methodological and genetic factors.

Among different models, when single SAN cell data collected in control conditions are considered, a large variability in cell capacitance, spontaneous rate, and kinetics features of the $I_{\mathrm{f}}$ current is observed among different models (Herrmann et al., 2007; Hoesl et al., 2008; Baruscotti et al., 2011). This variability is not a specific feature of knockout model studies, since it is largely present throughout the whole SAN cell literature (Boyett et al., 2000; Baruscotti et al., 2005; Mangoni and Nargeot, 2008). Whether this difference arises from a biased selection of specific cells is difficult to establish.

Upon physical exercise, or under isoprenaline stimulation, all HCN4 KO models display heart/cell rate accelerations which are not different from those elicited in control mice. Despite the similar acceleration, the maximal rate attained by the cardiac-specific $\mathrm{KO}$ mice model is substantially lower than that elicited in control and in complete or HCN4-restricted mice (Herrmann et al., 2007; Hoesl et al., 2008; Baruscotti et al., 2011); this is at least in part due to the fact that cardiac-specific $\mathrm{KO}$ mice have a lower basal rate. While taken at face value the permanence of modulation in cardiac-specific KO mice apparently suggests that HCN4 channels are not responsible for this modulation, this conclusion is contradicted by the evidence that the remaining $I_{\mathrm{f}}$ current in cardiac $\mathrm{HCN} 4 \mathrm{KO}$ mice is still amply modulated, and therefore can still contribute to iso-induce acceleration.

Although the experimental data amongst models are substantially different, we believe that an organ-specific gene ablation is the correct technique to investigate functional roles of mechanisms restricted to the organ itself. We also think that the ultimate purpose of a $\mathrm{KO}$ mouse model is to improve the understanding of the physiological aspects and pathological consequences in humans; our model is adequate to the purpose, since results obtained with the mouse $\mathrm{KO}$ model correspond to results obtained in humans, where it is known that a reduction of the $I_{\mathrm{f}}$ current either resulting from genetic mutations (Baruscotti et al., 2010b) or pharmacological blockade (DiFrancesco and Camm, 2004) leads to sinus bradycardia.

\section{INDUCIBLE TRANSGENIC MODELS}

The role of HCN4 channels in the adult heart has been evaluated also by Alig et al. (2009) who developed a transgenic mouse model with an $\alpha$-MHC promoter and a Tet-Off system-controlled cardiac-specific expression of an engineered human HCN4 subunit carrying a mutation previously identified in a patient with
SAN dysfunction (hHCN4-573X; Schulze-Bahr et al., 2003). The patient had marked sinus bradycardia $(41 \mathrm{bpm})$ and intermittent episodes of atrial fibrillation; a diagnosis of idiopathic sinus node dysfunction was made and a pacemaker was implanted. In vitro experiments based on patch-clamp-studies of the heterologously expressed mutant channels showed that the mutation abolished the cAMP-dependent regulation of HCN4 channels in a dominant negative manner (Schulze-Bahr et al., 2003). This model therefore did not induce an HCN4 knockout, but rather conferred to cardiac, and in particular to SAN cells, the presence of a mutated human HCN4 subunit which is fully insensitive to cAMP modulation.

Analysis of the ECG of conscious animals overexpressing the mutant hHCN4-573X channels revealed that the heart rate at rest was some $20 \%$ slower than that of control mice and no changes in PQ and QTc intervals were observed. In transgenic mice physical exercise was still able to elicit a positive modulation of heart rate, although to a significantly lesser degree than that observed in control mice exposed to a similar activity. The $I_{\mathrm{f}}$ current recorded in transgenic SAN cells exhibited slower activation kinetics and a negative shift of about $20 \mathrm{mV}$ of its voltage-dependence. Spontaneous oscillations of these cells were also severely impaired since most of the cells were either quiescent $(\sim 28 \%)$ or showed an arrhythmic behavior $(\sim 61 \%)$ consisting in periods of sub-threshold membrane potential oscillations followed by regular firing though at a reduced rate. Regular firing was observed only in $11 \%$ of the cells investigated. Iso application resulted in pacing acceleration and restoration of regular pacemaker activity in arrhythmic mutant cells, although maximal rates were significantly slower than in controls cells.

This model (Alig et al., 2009) is substantially different from previous inducible models and therefore trying to compare the results would be partially inappropriate. Nevertheless, in these mice the functionality of sinoatrial $I_{\mathrm{f}}$ current was severely impaired due to a negative shift of its voltage-dependence and a lack of cAMP modulation; thus, the conclusion that a reduced contribution of the $I_{\mathrm{f}}$ current leads in mice to bradycardia and chronotropic incompence is compatible with the results from our $\mathrm{KO}$ model (see above). On the other hand, the observation that most of single isolated SAN cells were quiescent points to a similarity with the results of Herrmann et al. (2007) and Hoesl et al. (2008).

The transgenic hHCN4-573X mouse model was also used by Marger et al. (2011) to investigate the role of HCN4 channels in AVN cells. This study showed that while basal spontaneous rate of transgenic AVN cells was reduced when compared to control cells, the maximal rates attained under Iso stimulation was not different between the two groups. While cells isolated from the SAN and the AVN of hHCN4-573X mice display similarly reduced basal rates, their response to maximal stimulation is clearly different although the underlying mechanism are not clear.

\section{MOUSE MODELS OF INDUCIBLE KNOCKOUT OF SAN CELLS}

Recently Herrmann et al. (2011a) developed a mouse model where it is possible to eliminate in an inducible manner HCN4expressing cardiomyocytes. The model was obtained by crossing a mouse line with the Cre inserted into the ATG codon of the Hcn4 gene (Herrmann et al., 2007; Hoesl et al., 2008) with a ROSA-eGFPDTA line able to express Diphtheria Toxin (DT) upon Cre-induced 
removal of a floxed stop sequence. Tamoxifen-induced activity of DT leads to a dose-dependent elimination of SAN cells and to their substitution with collagen fibers. Despite the large differences between this model and the inducible and cardiac-specific HCN4 KO model developed by our group (Baruscotti et al., 2011), the similarities of the phenotypic manifestations are many. In freely moving conscious mice the induction of DT (five consecutive days of tamoxifen injection) caused a substantial bradycardia $(-40 \%$ : from 493 to $275 \mathrm{bpm}$ ) comparable with that reported in our model (50\% reduction). Isoprenaline administration $(0.5 \mathrm{mg} / \mathrm{kg}$ i.p.) increased heart rate in both control (by $199 \mathrm{bpm}$ ) and DTexpressing mice (by $69 \mathrm{bpm}$ ) and the maximal value attained by DT-expressing mice was $447 \mathrm{bpm}$, a value which is similar to that reported in our experiments ( $\sim 486 \mathrm{bpm}$, Iso $0.1 \mathrm{mg} / \mathrm{kg}$ i.p.).

Together with bradycardia, the DT-expressing mice also showed additional arrhythmic features such as: increased PR interval, complete heart block, sino-atrial pauses and supraventricular or ventricular tachycardia. Whether this model is adequate to describe the primary features of the age-related sick sinus syndrome is still a matter of debate (Morris et al., 2011). As noted above the destruction of HCN4-expressing cells also impacts onto the AV node conduction of the impulse as verified by the increase of the PR interval, and remarkably this effect was observed in the model of Baruscotti et al. but no in other models (Herrmann et al., 2007; Hoesl et al., 2008; Alig et al., 2009).

\section{ROLE HCN2 AND HCN1 IN ADULT MICE}

The presence of the HCN2 isoform in the mouse adult heart is mostly confined to the ventricle, while in the atria and in the SAN HCN2 expression is hardly detectable. Despite the limited expression, experiments with both global and cardiac-specific constitutive HCN2-deficient mouse models (Ludwig et al., 2003) have revealed a sinus dysrhythmic pattern. In addition, global HCN2 KO mice were also affected by absence seizures. It is interesting to note that these data are in agreement with results in humans from our laboratory showing that a loss-of-function point mutation in the HCN2 C-linker is associated with a form of generalized epilepsy with recessive inheritance (DiFrancesco et al., 2011).

ECG analysis revealed that despite control and $\mathrm{HCN} 2 \mathrm{KO}$ mice had similar cardiac rates at rest (531 vs. 510 bpm), the HCN2deficient animals displayed a much increased RR variability at rest and during normal activity probably due to a dysfunction of the SAN. RR variability measured as the Standard Deviation of RR (SDRR) interval was $7.1 \mathrm{~ms}$ in control and in the range 14-17.1 ms in mice lacking HCN2 subunits. Upon maximal stimulation (Iso or physical activity) HCN2 KO mice were able to reach maximal rates similar to those of control mice $(>670 \mathrm{bpm})$ and the observed sinus dysrhythmia disappeared (SDRR in the range 3$5 \mathrm{~ms}$ for both groups). Experiment in isolated SAN cells revealed a decrease of about $30 \%$ of the $I_{\mathrm{f}}$ current density, significantly slower activation kinetics of the current, and a shift of about $5 \mathrm{mV}$ of the maximum diastolic potential to hyperpolarized values in global KO mice myocytes. Since the remaining (non-HCN2) $I_{\mathrm{f}}$ current in $\mathrm{KO}$ cells was still modulated by cAMP, these data indicate the HCN2 isoform contributes to cardiac pacemaking activity of SAN cells mainly at rest and under non-stimulated conditions.
A generalize knockout HCN1 mouse model was developed by (Nolan et al., 2003), and the authors report significant deficits in neuronal process related to spatial memory and learning ability. Since no embryo lethality or anatomical and functional alterations of the adult heart are reported it can be assumed that knockout of HCN1 subunits does not have a major impact on the heart. This evidence is in agreement with a limited presence of $\mathrm{HCN} 1$ proteins in the heart reported by some authors (Liu et al., 2007; Brioschi et al., 2009); however it must be noted that in some other reports HCN1 signal has been strongly detected in the SAN (Herrmann et al., 2011b).

\section{ROLE OF HCN3 IN ADULT/EMBRYONIC MICE}

The HCN3 isoform has been investigated less deeply than other isoforms in the cardiac field mostly because this isoform was initially thought to be expressed in neuronal and other types of tissue, but less so in cardiac tissue. Currently very few studies of the electrical properties of homomeric $\mathrm{HCN} 3$ channels have been carried out (Chaplan et al., 2003; Mistrik et al., 2005; Stieber et al., 2005). The presence of HCN3 mRNA and protein in SAN cells has been investigated so far only in rodents and there is no indication of a positive signal (Moosmang et al., 2001; Huang et al., 2007; Liu et al., 2007; Fenske et al., 2011; Herrmann et al., 2011b). There is on the other hand contrasting evidence concerning the expression of HCN3 in the working myocardium. Some groups failed to detect positive signals by in situ hybridization and real time PCR in mice and rat hearts (Moosmang et al., 2001; Huang et al., 2007; Herrmann et al., 2011b), while other found a weak RT-PCR positive signal in mouse heart and ventricles (Marionneau et al., 2005; Mistrik et al., 2005). Despite the positive mRNA identification Mistrik et al. (2005) failed to confirm the presence of HCN3 proteins likely because the signal was below the detection level. On the other hand, Fenske et al. (2011) reported positive mRNA identification in working myocardium and positive protein identification in mouse ventricles and generated a global and constitutive HCN3 knockout mouse by ablating the exon 2 of the Hcn 3 gene. Since $\mathrm{HCN} 3$-deficient mice were born at the expected Mendelian ratios with normal mice, it can be concluded that this isoform is not relevant for cardiac formation and development. In agreement with the lack of HCN3 mRNA and protein in the SAN, ECGs recorded from freely moving $\mathrm{HCN} 3$-deficient mice did not reveal anomalies in sinus rhythm. Important evidence supporting a contribution of the $\mathrm{HCN} 3$ isoform to the physiology of the working myocardium comes from the finding that at low heart rates (mean of $460 \mathrm{bpm}$ ) significant increases in the T-wave amplitude $(+63.5 \%)$ and duration $(+15 \%)$ and in the QT interval $(+12 \%)$ were detected. Patch-clamp analysis of epicardial cells from HCN3 KO mice showed a substantial shortening of the action potential duration (both APD75 and APD90) and a $\sim 30 \%$ reduction of the $I_{\mathrm{f}}$ current. Analysis of the steady-state voltage-dependence of the HCN3 channels revealed that at the cell resting voltage $(-85 \mathrm{mV})$ about $25-30 \%$ of the channels are in the conducting state. This piece of information, and the extremely slow kinetic of deactivation allow to formulate the hypothesis that the HCN3 component of the ventricular epicardial $I_{\mathrm{f}}$ current is active throughout the entire action potential and exerts its functional action by counteracting the $\mathrm{K}+$ current-driven late repolarization of epicardial cells. 
While these data certainly highlight a novel contribution of pacemaker channel to cardiac function we believe that there are some points that need to be addressed: (1) the contrasting reports in the literature regarding the presence of the HCN3 isoform in the heart pose the question as whether the results of this model can be generalized; (2) as pointed out by the same authors it is still to be determined why the phenotypic manifestations can only be observed in epicardial cells given that endocardial cells also express $\mathrm{HCN} 3$ proteins; (3) last but not the least is to verify whether HCN3 isoforms are also present in human epicardial cardiomyocytes.

\section{CONCLUSIONS}

HCN channels represent an important source of depolarizing current in the heart, and the use of specific constitutive or temporally controlled deletion of different HCN isoforms has allowed to better understand the contribution of each isoform to the different functional aspects of cardiac myocytes.

Despite some variability, in the literature there is a general agreement that the HCN2 isoform is mostly confined to the ventricle; while in other cardiac district and especially in the SAN HCN2 channels are poorly expressed. The very limited contribution of $\mathrm{HCN} 2$ subunits to cardiac pacemaking is confirmed by the finding

\section{REFERENCES}

Alig, J., Marger, L., Mesirca, P., Ehmke, H., Mangoni, M. E., and Isbrandt, D. (2009). Control of heart rate by cAMP sensitivity of HCN channels. Proc. Natl. Acad. Sci. U.S.A. 106, 12189-12194.

Barbuti, A., Baruscotti, M., and DiFrancesco, D. (2007). The pacemaker current: from basics to the clinics. J. Cardiovasc. Electrophysiol. $18,342-347$

Baruscotti, M., Barbuti, A., and Bucchi, A. (2010a). The cardiac pacemaker current. J. Mol. Cell. Cardiol. 48, 55-64.

Baruscotti, M., Bottelli, G., Milanesi, R., Difrancesco, J. C., and DiFrancesco, D. (2010b). HCN-related channelopathies. Pflugers Arch. 460, 405-415.

Baruscotti, M., Bucchi, A., and DiFrancesco, D. (2005). Physiology and pharmacology of the cardiac pacemaker ("funny") current. Pharmacol. Ther. 107, 59-79.

Baruscotti, M., Bucchi, A., Viscomi, C., Mandelli, G., Consalez, G., GnecchiRusconi, T., Montano, N., Casali, K. R., Micheloni, S., Barbuti, A., and DiFrancesco, D. (2011). Deep bradycardia and heart block caused by inducible cardiac-specific knockout of the pacemaker channel gene Hcn4. Proc. Natl. Acad. Sci. U.S.A. 108, 1705-1710.

Biel, M., Wahl-Schott, C., Michalakis, S., and Zong, X. (2009). Hyperpolarization-activated cation channels: from genes to function. Physiol. Rev. 89, 847-885.
Blum, K., Briggs, A. H., DeLallo, L., Elston, S. F., and Ochoa, R. (1982). Whole brain methionineenkephalin of ethanol-avoiding and ethanol-preferring c57BL mice. Experientia 38, 1469-1470.

Boyett, M. R., Honjo, H., and Kodama, I. (2000). Thesinoatrial node, a heterogeneous pacemaker structure. Cardiovasc. Res. 47, 658-687.

Brioschi, C., Micheloni, S., Tellez, J. O., Pisoni, G., Longhi, R., Moroni, P., Billeter, R., Barbuti, A., Dobrzynski, H., Boyett, M. R., DiFrancesco, D. and Baruscotti, M. (2009). Distribution of the pacemaker HCN4 channel mRNA and protein in the rabbit sinoatrial node. J. Mol. Cell. Cardiol. 47, 221-227.

Bryant, C. D., Zhang, N. N., Sokoloff, G., Fanselow, M. S., Ennes, H. S., Palmer, A. A., and McRoberts, J. A. (2008). Behavioral differences among C57BL/6 substrains: implications for transgenic and knockout studies. J. Neurogenet. 22, 315-331.

Bucchi, A., Baruscotti, M., Robinson, R. B., and DiFrancesco, D. (2007). Modulation of rate by autonomic agonists in SAN cells involves changes in diastolic depolarization and the pacemaker current. J. Mol. Cell. Cardiol. 43, 39-48.

Chandler, N. J., Greener, I. D., Tellez, J. O., Inada, S., Musa, H., Molenaar, P., DiFrancesco, D., Baruscotti, M., Longhi, R., Anderson, R. H., Billeter, R., Sharma, V., Sigg, D. C., Boyett, M. R., and Dobrzynski, H. (2009). Molecular architecture of the human

that the heart rates of $\mathrm{HCN} 2 \mathrm{KO}$ mice at rest and under maximal chronotropic modulation do not differ from those of control animals. Furthermore HCN2 are not functionally essential to heart formation during embryogenesis and maturation.

HCN3 subunits have long been regarded as little relevant to cardiac activity. Lately however ECG recordings in global and constitutive $\mathrm{HCN} 3 \mathrm{KO}$ mice have been reported to display alterations of the T-wave and of the QT interval. Interpretation of these data has led to the hypothesis that $\mathrm{HCN} 3$ channels represent a source of ventricular background current which opposes to the repolarizing process at the end of the ventricular APs.

HCN4 is by far the most important isoform in the heart, and its presence is most abundant in the SAN where HCN4 represents about $80 \%$ of the total HCN isoforms. Several HCN4 KO and transgenic mouse models have been developed and results are extremely variable (Table 1). Results with the cardiac-specific and inducible knockout model indicate that the HCN4 current provides a fundamental contribution to basal heart rate maintenance and modulation since its removal leads to basal bradycardia and a strongly reduced response to sympathetic stimulation. Furthermore the HCN4 current plays a critical role also in AV node conduction.

sinus node: insights into the function of the cardiac pacemaker. Cir culation 119, 1562-1575.

Chandra, R., Portbury, A. L., Ray, A., Ream, M., Groelle, M., and Chikaraishi, D. M. (2006). Beta1adrenergic receptors maintain fetal heart rate and survival. Biol. Neonate 89, 147-158.

Chaplan, S. R., Guo, H. Q., Lee, D. H. Luo, L., Liu, C., Kuei, C., Velumian, A. A., Butler, M. P., Brown, S. M., and Dubin, A. E. (2003). Neuronal hyperpolarization-activated pacemaker channels drive neuropathic pain. J. Neurosci. 23, 1169-1178.

Christoffels, V. M., Smits, G. J., Kispert, A., and Moorman, A. F. (2010). Development of the pacemaker tissues of the heart. Circ. Res. 106, 240-254.

DeHaan, R. L. (1965). Development of pacemaker tissue in the embryonic heart. Ann. N. Y. Acad. Sci. 127, 7-18.

DiFrancesco, D. (2010). The role of the funny current in pacemaker activity. Circ. Res. 106, 434-446.

DiFrancesco, D., and Camm, J. A. (2004). Heart rate lowering by specific and selective I(f) current inhibition with ivabradine: a new therapeutic perspective in cardiovascular disease. Drugs 64, 1757-1765.

DiFrancesco, D., Ferroni, A., Mazzanti, M., and Tromba, C. (1986). Properties of the hyperpolarizing-activated current (if) in cells isolated from the rabbit sino-atrial node. J. Physiol. 377, 61-88.

DiFrancesco, D., and Noble, D. (2012a). Rebuttal: The funny current in the context of the coupled clock pacemaker cell system. Heart Rhythm 9, 457-458.

DiFrancesco, D., and Noble, D. (2012b). The funny current has a major pacemaking role in the sinus node. Heart Rhythm 9, 299-301.

DiFrancesco, J. C., Barbuti, A., Milanesi, R., Coco, S., Bucchi, A., Bottelli, G., Ferrarese, C., Franceschetti, S., Terragni, B., Baruscotti, M., and DiFrancesco, D. (2011). Recessive loss-of-function mutation in the pacemaker HCN2 channel causing increased neuronal excitability in a patient with idiopathic generalized epilepsy. J. Neurosci. 31, 17327-17337.

Dobrzynski, H., Nikolski, V. P., Sambelashvili, A. T., Greener, I. D., Yamamoto, M., Boyett, M. R., and Efimov, I. R. (2003). Site of origin and molecular substrate of atrioventricularjunctional rhythm in the rabbit heart. Circ. Res. 93, 1102-1110.

Espinoza-Lewis, R. A., Yu, L., He, F., Liu, H., Tang, R., Shi, J., Sun, X., Martin, J. F., Wang, D., Yang, J., and Chen, Y. (2009). Shox 2 is essential for the differentiation of cardiac pacemaker cells by repressing Nkx2-5. Dev. Biol. 327, 376-385.

Fenske, S., Mader, R., Scharr, A., Paparizos, C., Cao-Ehlker, X., Michalakis, S., Shaltiel, L., Weidinger, M., Stieber, J., Feil, S., Feil, R., Hofmann, F. Wahl-Schott, C., and Biel, M. (2011). $\mathrm{HCN} 3$ contributes to the ventricular action potential waveform in the murine heart. Circ. Res. 109, 1015-1023. 
Garcia-Frigola, C., Shi, Y., and Evans, S. M. (2003). Expression of the hyperpolarization-activated cyclic nucleotide-gated cation channel HCN4 during mouse heart development. Gene Expr. Patterns 3, 777-783.

Han, W., Bao, W., Wang, Z., and Nattel, S. (2002). Comparison of ion-channel subunit expression in canine cardiac Purkinje fibers and ventricular muscle. Circ. Res. 91, 790-797.

Harzheim, D., Pfeiffer, K. H., Fabritz, L., Kremmer, E., Buch, T., Waisman, A., Kirchhof, P., Kaupp, U. B., and Seifert, R. (2008). Cardiac pacemaker function of HCN4 channels in mice is confined to embryonic development and requires cyclic AMP. EMBO J. 27, 692-703.

Hayashi, S., and McMahon, A. P. (2002). Efficient recombination in diverse tissues by a tamoxifeninducible form of Cre: a tool for temporally regulated gene activation/inactivation in the mouse. Dev. Biol. 244, 305-318.

Herrmann, S., Fabritz, L., Layh, B., Kirchhof, P., and Ludwig, A. (2011a). Insights into sick sinus syndrome from an inducible mouse model. Cardiovasc Res. 90, 38-48.

Herrmann, S., Layh, B., and Ludwig, A. (2011b). Novel insights into the distribution of cardiac HCN channels: an expression study in the mouse heart. J. Mol. Cell. Cardiol.51, 997-1006.

Herrmann, S., Stieber, J., Stockl, G., Hofmann, F., and Ludwig, A. (2007). HCN4 provides a "depolarization reserve" and is not required for heart rate acceleration in mice. $E M B O J$. 26, 4423-4432.

Hoesl, E., Stieber, J., Herrmann, S., Feil, S., Tybl, E., Hofmann, F., Feil, R., and Ludwig, A. (2008). Tamoxifeninducible gene deletion in the cardiac conduction system. J. Mol. Cell. Cardiol. 45, 62-69.

Huang, X., Yang, P., Du, Y., Zhang, J., and Ma, A. (2007). Age-related downregulation of HCN channels in rat sinoatrial node. Basic Res. Cardiol. 102, 429-435.

Ishii, T. M., Takano, M., Xie, L. H., Noma, A., and Ohmori, H. (1999). Molecular characterization of the hyperpolarization-activated cation channel in rabbit heart sinoatrial node. J. Biol. Chem. 274, 12835-12839.

Kiselycznyk, C., and Holmes, A. (2011). All (C57BL/6) Mice are not Created Equal. Front. Neurosci. 5:10. doi:10.3389/fnins.2011.00010
Lakatta, E. G., and DiFrancesco, D. (2009). What keeps us ticking: a funny current, a calcium clock, or both? J. Mol. Cell. Cardiol. 47, 157-170.

Liu, J., Dobrzynski, H., Yanni, J., Boyett, M. R., and Lei, M. (2007). Organisation of the mouse sinoatrial node: structure and expression of HCN channels. Cardiovasc. Res. 73, 729-738.

Ludwig, A., Budde, T., Stieber, J., Moosmang, S., Wahl, C., Holthoff, K., Langebartels, A., Wotjak, C., Munsch, T., Zong, X., Feil, S., Feil, R., Lancel, M., Chien, K. R., Konnerth, A., Pape, H. C., Biel, M., and Hofmann, F. (2003). Absence epilepsy and sinus dysrhythmia in mice lacking the pacemaker channel HCN2. EMBO J. 22, 216-224.

Mangoni, M. E., and Nargeot, J. (2008). Genesis and regulation of the heart automaticity. Physiol. Rev. 88, 919-982.

Marger, L., Mesirca, P., Alig, J., Torrente, A., Dubel, S., Engeland, B., Kanani, S., Fontanaud, P., Striessnig, J., Shin, H. S., Isbrandt, D., Ehmke, H., Nargeot, J., and Mangoni, M. E. (2011). Functional roles of $\mathrm{Ca}(\mathrm{v}) 1.3$, $\mathrm{Ca}(\mathrm{v}) 3.1$ and $\mathrm{HCN}$ channels in automaticity of mouse atrioventricular cells: insights into the atrioventricular pacemaker mechanism. Channels (Austin) 5, 251-261.

Marionneau, C., Couette, B., Liu, J., Li, H., Mangoni, M. E., Nargeot, J., Lei, M., Escande, D., and Demolombe, S. (2005). Specific pattern of ionic channel gene expression associated with pacemaker activity in the mouse heart. J. Physiol. (Lond.) 562, 223-234.

Matsuo, N., Takao, K., Nakanishi, K., Yamasaki, N., Tanda, K., and Miyakawa, T. (2010). Behavioral profiles of three C57BL/6 substrains. Front. Behav. Neurosci. 4:29. doi:10.3389/fnbeh.2010.00029

Mistrik, P., Mader, R., Michalakis, S., Weidinger, M., Pfeifer, A., and Biel, M. (2005). The murine HCN3 gene encodes a hyperpolarizationactivated cation channel with slow kinetics and unique response to cyclic nucleotides. J. Biol. Chem. 280, 27056-27061.

Moosmang, S., Stieber, J., Zong, X., Biel, M., Hofmann, F., and Ludwig, A. (2001). Cellular expression and functional characterization of four hyperpolarization-activated pacemaker channels in cardiac and neuronal tissues. Eur. J. Biochem. 268, 1646-1652.

Morris, G. M., Monfredi, O., and Boyett, M. R. (2011). Not so fast!
Sick sinus syndrome is a complex and incompletely understood disease that might prove hard to mode in animals. Cardiovasc. Res. 92, 178.

Nolan, M. F., Malleret, G., Lee, K. H., Gibbs, E., Dudman, J. T., Santoro, B., Yin, D., Thompson, R. F., Siegelbaum, S. A., Kandel, E. R., and Morozov, A. (2003). The hyperpolarization-activated $\mathrm{HCN} 1$ channel is important for motor learning and neuronal integration by cerebellar Purkinje cells. Cell 115, 551-564.

Portbury, A. L., Chandra, R., Groelle, M., McMillian, M. K., Elias, A. Herlong, J. R., Rios, M., RofflerTarlov, S., and Chikaraishi, D. M. (2003). Catecholamines act via a beta-adrenergic receptor to maintain fetal heart rate and survival. Am. J. Physiol. Heart Circ. Physiol. 284, H2069-H2077.

Schulze-Bahr, E., Neu, A., Friederich, P., Kaupp, U. B., Breithardt, G., Pongs, O., and Isbrandt, D. (2003). Pacemaker channel dysfunction in a patient with sinus node disease. $J$. Clin. Invest. 111, 1537-1545.

Shi, W., Wymore, R., Yu, H., Wu, J. Wymore, R. T., Pan, Z., Robinson, R. B., Dixon, J. E., McKinnon, D., and Cohen, I. S. (1999). Distribution and prevalence of hyperpolarizationactivated cation channel (HCN) mRNA expression in cardiac tissues. Circ. Res. 85, e1-e6.

Sohal, D. S., Nghiem, M., Crackower, M. A., Witt, S. A., Kimball, T. R., Tymitz, K. M., Penninger, J. M., and Molkentin, J. D. (2001). Temporally regulated and tissue-specific gene manipulations in the adult and embryonic heart using a tamoxifeninducible Cre protein. Circ. Res. 89 20-25.

Stieber, J., Herrmann, S., Feil, S., Loster J., Feil, R., Biel, M., Hofmann, F, and Ludwig, A. (2003). The hyperpolarization-activated channel HCN4 is required for the generation of pacemaker action potentials in the embryonic heart. Proc. Natl. Acad. Sci. U.S.A. 100 15235-15240.

Stieber, J., Stockl, G., Herrmann, S., Hassfurth, B., and Hofmann, F. (2005). Functional expression of the human HCN3 channel. J. Biol. Chem. 280, 34635-34643.

Stillitano, F., Lonardo, G., Zicha, S., Varro, A., Cerbai, E., Mugelli, A., and Nattel, S. (2008). Molecular basis of funny current (If) in normal and failing human heart. J. Mol. Cell. Cardiol. 45, 289-299.

Tellez, J. O., Dobrzynski, H., Greener, I. D., Graham, G. M., Laing, E., Honjo,
H., Hubbard, S. J., Boyett, M. R., and Billeter, R. (2006). Differential expression of ion channel transcripts in atrial muscle and sinoatrial node in rabbit. Circ. Res. 99, 1384-1393.

Thollon, C., Bedut, S., Villeneuve, N. Coge, F., Piffard, L., Guillaumin, J. P., Brunel-Jacquemin, C., Chomarat, P., Boutin, J. A., Peglion, J. L., and Vilaine, J. P. (2007). Use-dependent inhibition of hHCN4 by ivabradine and relationship with reduction in pacemaker activity. Br. J. Pharmacol. 150, 37-46.

Van Mierop, L. H. (1967). Location of pacemaker in chick embryo heart at the time of initiation of heartbeat. Am. J. Physiol. 212, 407-415.

Verkerk, A. O., van Borren, M. M., Peters, R. J., Broekhuis, E., Lam, K. Y., Coronel, R., de Bakker, J. M., Tan, H. L., and Wilders, R. (2007a). Single cells isolated from human sinoatrial node: action potentials and numerical reconstruction of pacemaker current. Conf. Proc. IEEE Eng. Med. Biol. Soc. 1, 904-907.

Verkerk, A. O., Wilders, R., van Borren, M. M., Peters, R. J., Broekhuis, E., Lam, K., Coronel, R., de Bakker, J. M., and Tan, H. L. (2007b). Pacemaker current (I(f)) in the human sinoatrial node. Eur. Heart J. 28, 2472-2478.

Vicente-Steijn, R., Passier, R., Wisse, L. J., Schalij, M. J., Poelmann, R. E., Gittenberger-de Groot, A. C., and Jongbloed, M. R. (2011). Funny current channel HCN4 delineates the developing cardiac conduction system in chicken heart. Heart Rhythm 8, 1254-1263.

Wiese, C., Grieskamp, T., Airik, R., Mommersteeg, M. T., Gardiwal, A., de Gier-de, V. C., Schuster-Gossler, K., Moorman, A. F., Kispert, A., and Christoffels, V. M. (2009). Formation of the sinus node head and differentiation of sinus node myocardium are independently regulated by Tbx18 and Tbx3. Circ. Res. 104, 388-397.

Yamamoto, M., Dobrzynski, H., Tellez, J., Niwa, R., Billeter, R., Honjo H., Kodama, I., and Boyett, M. R. (2006). Extended atrial conduction system characterised by the expression of the HCN4 channel and connexin45. Cardiovasc. Res. 72, 271-281.

Yasui, K., Liu, W., Opthof, T., Kada, K., Lee, J. K., Kamiya, K., and Kodama, I. (2001). I(f) current and spontaneous activity in mouse embryonic ventricular myocytes. Circ. Res. 88 , 536-542.

Zicha, S., Fernandez-Velasco, M., Lonardo, G., L'Heureux, 
N., and Nattel, S. (2005). Sinus node dysfunction and hyperpolarization-activated ( $\mathrm{HCN}$ ) channel subunit remodeling in a canine heart failure model. Cardiovasc. Res. 66, 472-481.

Conflict of Interest Statement: The authors declare that there search was conducted in the absence of any commercial or financial relationships that could be construed as a potential conflict of interest.

Received: 26 March 2012; accepted: 12 June 2012; published online: 02 July 2012.
Citation: Bucchi A, Barbuti A, DiFrancesco D and Baruscotti M (2012) Funny current and cardiac rhythm insights from HCN knockout and transgenic mouse models. Front. Physio. 3:240. doi: 10.3389/fphys.2012.00240

This article was submitted to Frontiers in Cardiac Electrophysiology, a specialty of Frontiers in Physiology.
Copyright (C) 2012 Bucchi, Barbuti, DiFrancesco and Baruscotti. This is an open-access article distributed under the terms of the Creative Commons Attribution Non Commercial License, which permits non-commercial use, distribution, and reproduction in other forums, provided the original authors and source are credited. 